\title{
On Life Cycle and Tourism Destination Management by Taking Yunnan Tourism as an Example
}

\author{
Caihong Zhang \\ Economic Management College, Pu'er University, Pu'er Yunnan 265000
}

Key words: Life cycle theory; Tourists marginal profit; Tourist destination

\begin{abstract}
Tourism destinations are affected by many factors, and spatial relations show different partnership forms from other competitions. Under the changes of life cycle theory constraints, two life cycle theories are got to fix tourist destination: life cycle theory with pure customers' factors and life cycle theory with human intervention. The above two theories are taken as the basis for Yunnan tourism practice and agriculture rotation theory, and rotation is feasible and has existence value in tourist destination management.
\end{abstract}

Tourist destination rotation is an ecological development concept for tourist destination and a continuous development pattern which carries out the planned development operation and management in turn for the tourist areas. Tourist destination's rotation border can set the starting moment by full travel capacity and tourists’ zero marginal profit, so it is operable.

\section{THE AMENDMENT OF LIFE CYCLE THEORY}

Life cycle represents a basic concept in the initial stage of biology, and this concept is mainly evolved from the biological process from birth, growth to death. People later simulate the life cycle with only biological significance and illustrate the process of market life cycle, and the resulting product is life cycle theory. It refers that the concrete product in the market will experience introduction, growth, maturity and decline stages as the organisms in nature. [1] This theory can live on the same application in tourism products, brand or destination giving priority to service.

But clearly tourism products are different from material products in a general sense, and the tourism product life cycle is more complex, especially in the recession phase. Tourism products have rebirth functions which are different from other products. Thereafter, Bart tourist destination life cycle theory implemented the correction at the end of traditional life cycle, [2] and divided the tourist destination life cycle into six stages: fumble, participation, growth, consolidation, stop, and decline. Then rebirth is added in the end.

Any theory requires the corresponding premises and assumptions. Tourist destination life cycle theory also needs the most basic prerequisite market environment and so on for typical tourist destination life cycle theory. Assume to take increasing life cycle theory as a constraint condition, on the basis of traditional life cycle theory correction, at least the following two useful tourism destination life cycle theories will be got.

A. Pure customers' factors life cycle theory

If the customers factors change among all the factors related to tourist destination and the rest are the same, namely assume that the destination growth will be only under the influence of demographic factors and restriction. The tourism destination life cycle will be consistent with customer population growth, and population reproduction cycle time is about 20 years. Then pure customers' factors life cycle in the tourist destination can be estimated. In the same cycle, the creation and depletion of tourist behavior is a gradual process, thus there will be an increasing curve at the beginning of each week and a decreasing curve at the end, so the overall distribution form is a bell. This theory shows that for a tourist destination, after 20 years operation and management, customer market will update all due to the regeneration of the population, and form a new customer market. 


\section{B. Life cycle theory with human intervention}

Generally speaking, the growth of tourism destination runs the described life cycle theory trajectory. But in order to achieve adequate tourism destination rest, people often target the intervention in the tourism destination development on purpose to maintain the sustainable development of scenic spots, and effectively extend the life cycle, for example, Shennongjia mountains were shut for two years, and there were local close-ups in mountain Huang.

If a destination is in recession, people usually use intervention to ensure it sufficient rest. Normally used means are inertial management strategy; limit the number of visitors and the shock therapy. To timely cut scale of tourists to the state of nature to the greatest extent. Through a period of tutelage, restore tourists' dimensions to the original level to promote healthier tourism destination than the original one.

\section{TOURIST DESTINATIONS ROTATION}

The important experience of Yunnan tourism construction has condensed energy in Yunnan province, and focused limited resources such as people, money, and material in our province. Every five years, a tourist destination will be introduced and created, and each time it achieves the success, which makes continuous selling point and scenic spots in Yunnan, from Xishuangbanna to Dali to Lijiang, Shangri-la, Tengchong...... Based on the thinking, a new development will be achieved. The selling points and highlights of tourism quantity in Yunnan are limited. In the process of rolling out tourism destination, all the tourism resource development may complete and the end becomes a starting point, and people return to the renaissance in Xishuangbanna tourism. Xishuangbanna then starts again to become a hot spot. The connections between rebirth and reincarnation will become an infinite loop of tourist destination.

Input reincarnation and circulation in Yunnan tourism destination development strategic thought, and the central idea of tourism destination is rotation idea, which refers to the only way and the law of sustainable development guarantee of the regional tourism. [3] The important theory to support the law is traditional agricultural ecological development ---- rotation. Rotation refers to taking turns, and the main content is that after a few years farming, soil fertility gradually disappears, and the living situation of vegetation in the soil is not ideal, thus forces people to develop new land and keeps the fallow state of original soil fertility depletion, and farm again after the soil recovered. Rotation is an ecological agriculture pattern, and the thought is no longer used in modern agriculture. Because mainly people use chemical fertilizer to endlessly supplement the soil fertility, but in the end, the result leads to the destruction of soil fertility, and eventually walks into a dead end. As a guide, travel is not a contemporary model of farming, and eventually gets to the path of death.

There is a deep connection between tourist destination whorl and life cycle. Life cycle in another perspective justifies the necessity and feasibility of tourism destination rotation. 20 years population growth cycle corresponds to a business cycle of the destination. After 20 years, tourist destination customers realize a full update. This situation shows that tourist market can consciously reserve new customers for tourism destination rotation, so there is no need to worry about customers. At the same time, life cycle theory with human intervention is an important theoretical basis for the necessity of tourism destination rotation. [4] Any tourist destination after a period of time's development all need rest aftercare, and the specific means is to shut down or restrict visitors.

\section{THE RELATIONSHIP BETWEEN TOURIST CAPACITY, MARGINAL PROFITS AND TOURISM DESTINATIONS ROTATION THOUGHT}

The key to tourist destination rotation from theory to practice is the rest time of tourism destination, which also is tourist destination rotation boundary, but at present there is no systematic theory calculation, so the article gives no implementation details. Of course, the rotation starting point of tourism destination development and management does not advocate tourist destination shock or instant fallow. Make sure that the tourism destination in rotation period is not suitable for excessive 
tourism marketing, and the most basic is also to limit the size of the tourists. [5] In general, the main measures of tourism destination rotation realization are inertia business strategy, and get into the stage of fallow period in a gradual way.

Find the boundary, the simple and direct method is to use tourist destination tourist capacity as rotation boundaries. Current measuring methods and technologies of tourism environment are more mature. The key factors of tourist environmental capacity also are many. The most basic ones are environment, society, and economic capacity. Depending on the importance of environmental capacity, under the weighted average method, solve comprehensive environmental capacity, and treat it as a tourist destination rotation boundary. If the total scale of tourists closes to the tourist destination tourist saturation value, consider the nurture of the region's culture.

Standing in the economic perspective, tourists' margin profit can be taken as a powerful tool rotation boundary. For tourism purposes, every visitor can be treated as a product, and tourists obvious have two important product features: costs and benefits. Tourism destination gets the corresponding income and also consumes a cost after the reception of visitors. [6] Based on marginal analysis theory, when the tourists' marginal theoretical value of tourist destination is zero, it will achieve the best scale of tourists with maximum income. When the number of tourists increases, tourism revenues decreases. If visitors scale breaches this critical point, it needs interest-bearing recuperation.

In the rotation border period to implement tourism destination, the operation of tourist sites and managers should not be cheated by immediate profits, and there is no appreciation of space completely in the tourism destination. Continual operation can cause the devaluation of the tourist destination; on the contrary, it achieves long-term benefits after rest. Reasonable rest will help tourism destination for more long-term growth and profits.

\section{YUNNAN TOURISM DESTINATION MANAGEMENT RESEARCH}

The rotation of Yunnan tourism destination comes from government's development strategy thought, rotation practice and theory. The government of Yunnan province and Tourism Bureau assigned a certain plan and steps for the development of tourist destinations in Yunnan province. In 1992 last century, there was a key development in Xishuangbanna and Dianzhong tourist areas in Yunnan. Before the mid-1980s, Kunming tourist reception number all closed to $70 \%$ of Yunnan tourism market. Then at the Tourism Strategy Session, the government put forward the end of Xishuangbanna and Yunnan tourism development, and the fiscal support transfer of tourism gradually to northwest Dali, Lijiang, Shangri-la, etc. Starting in 1999, after 8 years of development, the above three areas gradually became famous tourist business cards in our country, and from 1999 to 2005, the government began to develop Tengchong, the representative of western Yunnan tourism projects. Tengchong tourism began popular gradually, mainly having tourism projects such as hot springs and jewelry tour. Then the government again shifted target to Dianzhong tourism promotion to blend Dianzhong leisure and conferences elements of Yunnan tourism. [7] Till now, Yunnan province has achieved a relatively complete rotation cycle, and the target is in the southeast region and Guilin Karst natural heritage tourism, Dian northeast development, and Dian southwest development to gradually help Yunnan tourism develop into a complete full cycle of rotation.

\section{SUMMARY}

Tourist destination rotation is the ecological development of tourism destination, and this development philosophy has stronger operability, which can realize the continuous development of tourism destination. The development thought of tourism destination rotation is very simple, but the theoretical value of the thought is very strong. Rotation thoughts have extremely important guiding significance for regional tourist destination development, especially for our country tourism which is in start-up phase. Rotation thought has important guiding significance for long-term tourism development and management in various cities and provinces, or after one hundred years, our country's tourism will get lost and it is difficult to find the final destination. 


\section{FUND PROJECT}

Scientific Research Project of Pu'er University "Frontier Minority Areas Rural Tourism Resources Characteristic Evaluation and Development Strategy Research ---- Taking Yunnan Pu'er for Example" (Project Number: 2015 xjkt12)

\section{REFERENCE}

[1] Li Bowen. Life cycle theory and tourist destination rotation ---- Taking Yunnan tourism for example [J]. Journal of Guangxi University (Philosophy and Social Sciences Edition), 2008, 11:24-27.

[2] Ge Chengwei, Litao. Research on tourist destination life cycle and depth development ---Taking Taishan scenic area for example [J]. Journal of Modern Business, 2013,09:120-121.

[3] Yang Xiuping, Weng Gangmin. Sustainable urban tourism environment carrying management innovation research [J]. Journal of Human Geography, and Practices of 2014:146-153.

[4] Li Yanqin, Shu Sheng. China's frontier study under the focus of travel [J]. Journal of Geographical Research, 2015 01:407-421.

[5] Yang Xiaozhong, Peng Min. Border tourism research review and prospects [J]. Journal of Human Geography, 2012, 2012:19-24 + 93.

[6] Lu Lin, Bao Jie. Qiandao lake tourism destination evolution process and mechanism based on the theory of dissipative structure [J]. Journal of Geography, 2010,06: 755-768.

[7] Xu Honggang, Xue Dan. Tourism destination bionics spatial relationship research ---- Taking Xidi and Hong village, the ancient villages in Anhui province for example [J]. Journal of Geographical Science, 2011, 12:1518-1524. 